\title{
ГАРМОНИЗИРУЮЩЕЕ ВОЗДЕЙСТВИЕ ОСВОЕНИЯ ИНОЯЗЫЧНОЙ КУЛЬТУРЫ НА ЛИЧНОСТЬ БУДУЩЕГО УЧИТЕЛЯ В УСЛОВИЯХ КУЛЬТУРОСООБРАЗНОГО ОБРАЗОВАНИЯ
}

\section{HARMONIZING INFLUENCE OF MASTERING A FOREIGN LANGUAGE CULTURE ON THE PERSONALITY OF A FUTURE TEACHER IN THE CONTEXT OF CULTURE-RELATED EDUCATION}

\section{E. Morozova}

Summary: The paper analyzes the process of mastering a foreign language culture and its influence on the development of the future teacher's personality, capable of professional self-analysis and the search for a personally significant meaning of the profession, which is based on instilling in the growing generations moral qualities and a tolerant attitude to the hierarchy of value orientations of another person, which are the key to the prosperity of any state.

The article also examines the potential of the process of cultivating a tolerant attitude to the negative manifestations of another culture, which makes it possible to effectively implement the development of a foreign language culture and develop a personality capable of pluralism of opinions and informed choices.

Keywords: influence, development, foreign language culture, culturerelated education, highly moral personality.

\author{
Морозова Елена Николаевна \\ К.п.н., дочент, учитель, МАОУ СОШ №12, г. Тобольск \\ elena.morozova.76@mail.ru
}

Аннотация: В работе анализируется процесс освоения иноязычной культуры и его влияние на развитие личности будущего учителя, способной к профессиональному самоанализу и поиску личностно значимого смысла профессии, в основе которого лежит привитие подрастающим поколениям нравственных качеств и толерантного отношения к иерархии ценностных ориентаций другого человека, являющихся залогом процветания любого государства. В статье также рассматриваются потенциальные возможности процесса воспитания терпимого отношения к негативным проявлениям иной культуры, позволяющие эффективно реализовывать освоение иноязычной культуры и развивать личность, способную к плюрализму мнений и осуществлению осознанного выбора.

Ключевые слова: воздействие, освоение, иноязычная культура, культуросообразное образование, высоконравственная личность. реодолеть глобальный мировой кризис, охвативший все области жизнедеятельности, а также тотальную утрату ценностей как личностного, так и социального характера, можно, реализуя актуальную потребность в духовном объединении народов, населяющих планету. Игнорирование этой необходимости может привести к весьма негативным последствиям, таким как разделение сил, интенсифицирующиеся и непримиримые контрадикции, в которых заключается квинтэссенция разрушаемого «планетарного сознания» XXI столетия.

Только образование может выступить тем инструментом, при помощи которого можно будет нейтрализовать возрастающее напряжение во взаимоотношениях между людьми, обусловленное непреодолимой разницей в менталитете наций, народностей. Репрессивным искоренением инакомыслия и демократических начал. Сущностью образовательного процесса в современных условиях является воспитание не только разумного, но и высоконравственного, духовно обогащенного учителя, способного к поиску новых результатов познания, зна- ющего смысл своей активной, жизненной, целенаправленной позиции, принятию нестандартных решений, основанных не на мистических иррациональных догмах, уводящих от реалий жизни, а базирующихся на новой мировоззренческой основе, заключающейся в формировании у студентов целостной картины материального и духовного мира, способствующей осознанию принадлежности каждого из них к единому человеческому сообществу, осмысленной трансляции из поколения в поколение духовных, культурных, нравственных ценностей, отражающих как национальную самобытность народа, так и общечеловеческую направленность.

Основная цель образовательной сферы должна заключаться в том, чтобы взрастить Личность, способную жить и работать в совершенно новых, свободных и демократических, условиях. Это должна быть личность, готовая к сознательному и самостоятельному выстраиванию своей социальной жизни, признающая непререкаемый приоритет права человека на свою особую ментальность [2, с.127]. Очень важно, чтобы человек мог воспитать новое поколение, способное воспринимать и 
уважать общечеловеческие социальные ценности, культуру своей нации. Необходимо привить толерантное и уважительное отношение к представителям других национальностей и позволить личности осознать свою индивидуальную значимость в ходе трансформации духовных аспектов нынешней цивилизации, объединения, взаимодействия существующих народов.

Рассматривая наиболее эффективные средства трансформации нынешней системы образования в соответствии с последними требованиями мирового развития, следует отметить следующие. Важно формировать созидательное начало во взаимодействии в образовательной системе, стремиться к гуманитаризации образовательного пространства, приобщать учащихся к культуре, рассматривая ее как одухотворенное отражение сферы ценностей и смыслов человека, а также формировать «живое знание» (В.П. Зинченко), стремясь заменить рутину на «живое взаимодействие» (В.В. Зеньковский) с каждым, участвующим в образовательном процессе. Важно трансформировать знания в чистом виде так, чтобы они стали живыми мыслями и эмоциями человека (В.А. Сухомлинский).

Смысл в качестве личного восприятия участников образовательной деятельности к усваиваемому материалу может зародиться лишь на границе двух сознаний в виде отношений между этими сознаниями. В связи с этим выстраивание образовательного процесса в форме диалога, в котором отражается воспитательное начало, который обеспечивает естественную интеграцию, позволяет сохранить самобытность каждой нации (в том числе и самых немногочисленных), формирует психологически положительные условия для его развития и нивелирует иллюзии касательно самодостаточности такой самобытности, выливающиеся в самоизоляцию и сепаратизм, может поспособствовать гуманизации современного образования за счет применения в нем человеческих оснований.

Изучив научные источники по рассматриваемой теме, можно говорить о наличии нескольких важных теорий, рассматривающих особенности соотношения между образовательной и культурной сферами. В частности, одни ученые рассматривают образовательный процесс как культуросообразное и культурообразующее пространство. Среди них В.С. Библер, Е.В. Бондаревская, А.Г. Валицкая, О.С. Газман, В.И. Загвязинский, Н.Б. Крылова и другие. Остальные ученые говорят о том, что образование должно ориентироваться на культуру как ключевую цель и содержание образовательной системы. Задача образования на сегодняшний день - найти ценностно-гносеологический фундамент отечественной школы, ориентироваться на гуманистические основания и стремление к всестороннему личностному развитию, гармонично сочетающееся с межкультурными, этнона- циональными и общечеловеческими составляющими. Эту точку зрения высказывают исследователи Б.С. Гершунский, И.В. Бестужев-Лада, Ш.А. Амонашвили, А.М. Новиков, М.С. Каган и др.

В трудах исследователи подчеркивают, что в рамках культурного диалога культуросообразный образовательный и воспитательный процесс выражается как в трансляции культурных знаний и опыта, так и в их трансформации, которую производит внутренне-диалогическое, рефлексивное сознание человека. Результатом становится новое состояние индивида, его межкультурная направленность.

Следует отметить, что культуросообразное образование подразумевает новое толкование значения диалогического взаимодействия. В частности, согласно новой концепции, диалог рассматривается не только в качестве рассуждения и противопоставления мыслей, но и прежде всего в качестве ориентированности на собеседника. Если речь идет о восприятии других культур, такая ориентированность должна быть рефлексивной. Необходимо понять, как выражается речевое поведение других национальностей и народов. Для этого необходимо уметь сопоставлять, анализировать и выделять сходства и различия. Кроме того, для того чтобы обеспечить гармонизирующее влияние культур на человека, осваивающего эту культуру, необходимо понять, воспринять и умножить ценности. Для этого нужно уметь объединять общечеловеческие и этнонациональные аспекты, применяя разнообразные методы толкования явлений или же событий. Человек должен быть способен к самостоятельному исследованию, сравнению фактов двух культур, из которых одна является его родной культурой, а вторая - изучаемая, чужая культура. Для этого необходимо. Чтобы культурные проявления стали частью знаний и опыта этого индивида, способного выразить свою эмоциональную реакцию при помощи как речевых, так и внеречевых средств.

Важный инструмент, при помощи которого можно реализовать смысл диалогического культурного взаимодействия, подразумевающий саморефлексию и привитие уважительного восприятия системы ценностей представителей других культур, а также способность участников коммуникативного взаимодействия к самовыражению и пр. - это изучение иноязычной культуры. Цель такого изучения состоит в том, чтобы породить взаимоотношения новой формации, достичь партнерских отношений в достижении единой образовательной цели, обеспечить взаимное образование участников образовательного процесса. Изучение иностранной культуры является многоуровневым.

На первом уровне необходимо выбрать и изучить иноязычные особенности, прививая терпимое отноше- 
ние к отрицательным явлениям в иностранной культуре, выработать устойчивый иммунитет к любым проявлениям ксенофобии.

На втором уровне позитивно оцениваемые специфики иностранной культуры необходимо оценить, принимая во внимание ее отрицательные черты.

На третьем уровне родные ценности трансформируются на почве конфронтации с изучаемыми ценностными установками иностранной культуры.

На четвертом уровне особенности иноязычной культуры проецируются на родную культуру с ее ценностями;

Пятый уровень - это реализация системной интеграции. В ее основе лежит нивелирование статуса новшества. При этом ценности иноязычной культуры более не воспринимаются как чужие и становятся органическим элементом родной культуры индивида. В ходе такой интеграции происходит осознанная переработка новшества, за счет чего иноязычная культура обретает характеристики родной культуры, отличающие ее от изначального прообраза.

При ознакомлении с культурой других национальностей неизбежно познаются их обычаи, которые служат источником для хранения и трансляции ценностей той или иной национальности. Понимая природу обычаев иноязычной культуры, индивид может воспринять аксиологическую шкалу представителей этой культуры. Специфика иноязычной культуры осознается в ходе ее изучения сопоставления с аксиологической системой родной культуры. Это дает индивиду возможность самоопределения в родной культуре, осознания себя как неотъемлемой ее части. В процессе отбора и восприятия иноязычных особенностей человек основывается на особенностях, свойственных процессу сопоставления разнородных объектов. Это, в частности:

1. Максимально глубокое осознание природы и важности слабо выраженных аксиологических единиц, существующих в родной культуре.

2. Схожий смысл, но разный механизм применения в деятельности.

3. Факт отсутствия сходных специфик в родной культуре.

В структуре аксиологических векторов каждого народов есть как позитивно оцениваемая культурная специфика, так и негативные ее проявления. В связи с этим, отбирая и воспринимая специфику иноязычной культуры, следует принимать во внимание указанные негативные проявления, так как это поможет сохранить позитивные ценности своей культуры. Привитие толерантного отношения (которое мы рассматриваем как факт признания наличия разнообразных культур, каж- дой из которых свойственны свои преимущества и недостатки, а также как множественность точек зрения как неизбежное явление в современных реалиях) к негативным проявлениям происходит следующим образом:

1. Понять и принять равноправие всех существующих в мире конфессий.

2. Осознать, что осуждать ценности и традиции другой культуры, исходя из аксиологической системы родной культуры, неэтично.

3. Необходимо определить осознание представителями других культур присутствия негативных проявлений в своей ценностной системе.

Упрочение устойчивости к таким явлениям, как шовинизм, расизм, национализм и пр., которому отводится огромное значение в формировании поликультурного индивида, для чего важно осознать содержательное наполнение любой иноязычной культуры, понять настоящее значение понятия «плюрализм» и выработать толерантное отношение к негативным проявлениям иных культур. Для этого необходимо:

1. Владеть собственными когнитивными средствами.

2. Прививать позитивные аттитюды, за счет которых индивид будет воспринимать и применять информацию, которая не подтверждает изначально сформировавшиеся стереотипы.

3. Формировать все условия для того, чтобы индивид понял свою предубежденность.

4. Рассказывать лицам о тактике борьбы с подсознательным реагированием на формирующиеся стереотипы с целью развивать гибкость в том числе предубеждений, практически не поддающихся контролю собственной воли.

5. Сплачивать индивидов вокруг единых целей. Это поможет сместить акцент с этноцентристкой позиции на сферу межличностных коммуникаций.

6. Формировать условия, способствующих убежденности в положительности родной культуры. Это поможет нивелировать воздействие механизмов психологической защиты, результатом которых может стать агрессивное и ненавистническое отношение к представителям других культур, а также исключить закономерность влияния такого механизма, как каузальная атрибуция, во взаимодействии представителей разных культур.

7. Активизировать общественное сознание с целью определить валентность ксенофобии и шовинизма, как латентного вида нетерпимости, инструмента искоренения взаимодействия с представителями других культур и обосновать подробное раскрытие результатов такого хода разрешения так проблемы взаимодействия между разными народностями и национальностями.

8. Нарастить межличностные взаимодействия и привить понимание того факта, что между своими и чужими отмечаются самые разнообразные сход- 
ные черты и ценности. Это позволит изменить отношение к важности социальных категорий для разделения индивидов, а, значит, обеспечит персонализацию и декатегоризацию.

Рассмотрим факторы, обеспечивающие эффективность прохождения этого уровня изучения иноязычной культуры.

- субъект пошагово узнает специфику поведенческих характеристик лиц, представляющих другую культуру;

- эмоционально позитивное восприятие субъектом процесса изучения иноязычной культуры;

- со временем у субъекта, изучающего иноязычную культуру, стираются языковые и поведенческие преграды в ходе взаимодействия.

Желание человека самосовершенствоваться реализуется через выборочное восприятие обогащающих характеристик иноязычной культуры. На этой стадии изучения иноязычной культуры индивид получает навыки принятия осмысленных им ценностей чужой культуры как основополагающих своих «жизненных регуляторов». [3, с.52] Вера в то, что человек может трансформировать окружающую его реальность на базе нового отношения к аксиологической системе своей культуры помогает перенести обогащающие свойства на человека и его мироощущение. Людям свойственно стремление надевать маски играть разные роли, которые характерны для той или иной макси. В этом отношении нам бы хотелось процитировать бельгийского исследователя Ж. Нюттена. в частности. Он утверждал, что даже если смотреть на жизнь как на театр масок, необходимо помнить, что любая маска рано или поздно прирастает к лицу того, кто ее носит. [4, с.74] Мы считаем, что врастание маски в человеческое лицо не может негативно сказаться на человеке, если такая маска обладает обогащающим действием. Процесс трансформации чужого в статус приобретенного является непростым. С позиций психологии, для того чтобы решить эту задачу, следует внушить себе факт восприятия тех или иных специфик иноязычной культуры. Кроме того, следует преодолевать внутренние духовные барьеры, которые не позволяют новой черте характера стать частью личности. Для того чтобы реализовать этот уровень, следует соблюдать определенные условия:

- отбор особого культурологического материала в процессе диалога представителей разных культур;

- учет личностного разнообразия субъектов родной и ИК;

- гуманистическое взаимодействие участников диалога культур.

Факторы, обеспечивающие результативность прохождения этого процесса, заключаются в следующем:
1. Численный прирост инноваций. При этом имеются в виду как экзогенные, так и эндогенные инновации.

2. Численность слабых, несущественных и неэффективных инноваций, которые подрывают восприимчивость обычаев, которые ускоряют вливание наиболее мощных ценностей иноязычной культуры.

3. Степень адаптации аксиологических систем иноязычной культуры к особенностям культуры индивида, ее изучающего.

4. Ориентиры культурного развития, транслирующие инновации, их общественно-политическая, а также экономическая характеристика.

Степень системной интеграции, трансформации аксиологической системы иноязычной культуры в неотъемлемую часть культуры индивида, ее воспринимающего, выявляется следующими способами:

1. Угасание в памяти социума того момента, когда была введена конкретная инновация.

2. Выявление временного отрезка, требующегося для того, чтобы инновации стали неотъемлемым компонентом родной культуры. Этот отрезок находится в зависимости от цикличности жизнедеятельности социума, которому транслируется иноязычная культура;

3. Выявление способности исконных, нерушимых аксиологических единиц своей культуры воспринимать инновации. В этом состоит их адаптивная мобильность;

Эффективность принятия внешних культурных импульсов представителями родной культуры заключается:

1. Большая роль, которую играет внешний импульс в процессе саморазвития родной культуры.

2. Соответствие аксиологической системы иноязычной культуры ценностно-идеологическому пространству реципиента.

3. Восприятие разными социальными группами, существующими в данной культуре, инноваций, транслируемых другой культурой.

4. Степень соответствия (как минимум отсутствие контрадикций) этнодифференцирующей и этноинтегрирующей составляющим культуры, воспринимающей ИК.

5. В целесообразности инноваций, которые должны соответствовать направлениям внутреннего поступательного развития культуры, принимающей аксиологическую систему иноязычной культуры;

В ходе оптимизации, улучшения и совершенствования способностей и потенциальных возможностей личности акцент постепенно смещается с пассивных позиций индивида к активным личным позициям в разрешении задач, которые перед ним поставлены. Ино- 
язычные характеристики в работе педагога возникают посредством:

1. Реформирование аксиологической шкалы своей культуры, учитывающее новые трансформации.

2. Обеспечение баланса между качественно новым формированием и аксиологической системой культуры-реципиента.

3. Способность перешагнуть через свое противление новым реформациям.

4. Установление рубежа между положительным воздействием и отрицательным влиянием иноязычной культуры.

5. Целесообразное сочетание разных с точки зрения смыслового наполнения ценностей своей и иноязычной культур.

Итак, на основании сказанного можно сделать вывод, что изучение и принятие иноязычной культуры следует рассматривать в качестве деятельности человека, цель которой - узнать специфику других культур и трансформировать в лучшую сторону окружающую реальность в соответствии с новыми качественными трансформациями в совокупности своих личностных характеристик. Эта цель должна быть с человеком в течение всей его жизни и в качестве функционального пространства, обеспечивающего развитие и взаимодействие всех компонентов иноязычной и родной культур.

На уровень действенности изучения иноязычной культуры воздействуют самые разнообразные факторы, которые срабатывают не по отдельности, а в обязательном взаимодействии. Конечно, самый значимый из этих факторов - это степень общественно-экономического развития, которой удалось достичь конкретному социуму и которое находит свое отражение во всех системных составляющих культуры этого социума. В роли второго по значимости фактора, помогающего сформировать психологически позитивные условия для восприятия иноязычной культуры, заключается в исторической ситуации, существующей в социуме на данный момент времени, а также вектор ее изменения, обуславливающий особенности этой культуры. На третьем месте находится фактор окружающей природной среды и изменений, в ней происходящих. Взаимосвязь, наличествующая между всеми названными факторами, влияющими на эффективность восприятия иноязычной культуры, не требует доказательств, если анализировать социальнокультурную эволюцию с точки зрения системного подхода, исключая эволюционизм, характерный для 19 века, в особенности тэйлоровского толкования [5, с.12]. каждой системе свойственна взаимная зависимость и взаимодействие составляющих ее компонентов. А значит, изменения, пусть даже незначительные, одного компонента всегда приводят к изменению остальных, а значит, и всей системы.

Подводя итог сказанному выше, считаем необходимым заострить внимание на позиции, согласно которой суть любой коммуникации состоит в том, чтобы обменяться нравственными ценностями, разделить чувства, эмоции и мысли представителя другой культуры, почувствовать духовное единение, «уточнить» себя, удовлетворить коммуникативные нужды, ведь именно в ходе коммуникации реализуется тончайшая потребность: это потребность человека в человеке.

Диалог в обучении, по М.М. Бахтину, доверие к чужому слову, ученичество, поиск глубинного смысла, согласие, наслаивание смысла на смысл, голоса на голос, усиление путем слияния (но не отождествление), дополняющее понимание, выход за пределы понимаемого [1, с.317]. Принимая во внимание характеристики сущности диалога, данные М.М. Бахтиным, можно сделать вывод о том, что содержание образования - это не только дидактически обработанный «сгусток» науки, предъявляемый участникам образовательного процесса в «храме науки», в первую очередь это реализация идеи диалога культур посредством освоения ИК как важнейшей парадигмы педагогического мышления, выражающей его гуманистическую и демократическую направленность.

\section{ЛИТЕРАТУРА}

1. Бахтин М.М. Эстетика словесного творчества. - М., 1986.

2. Гершунский Б.С. Философия образования. - М.: Московский психолого-педагогический институт, Флинта, 1998.

3. К Крылова Н.Б. Культурология образования. - М.: Народное образование, 2000.

4. Моргун В.Ф. Личность и игра // Проблемы освоения театральной педагогики в профессионально-педагогической подготовке будущего учителя. - Полтава, 1991.

5. Э. Тэйлор Первобытная культура. - М.: Соцэкгиз, 1939.

( ) Морозова Елена Николаевна (elena.morozova.76@mail.ru).

Журнал «Современная наука: актуальные проблемы теории и практики» 